\title{
A Miniature and Low-Power-Consumption Stress Measurement System for Embedded Explosive in Multilayer Target Penetration
}

\author{
Yu Hang, Fei Shang ${ }^{D}$, Shang Gao, Deren Kong ${ }^{(D)}$, and Xuehui Zhang \\ School of Mechanical Engineering, Nanjing University of Science and Technology, Nanjing 210094, China \\ Correspondence should be addressed to Fei Shang; shangfei23@126.com and Deren Kong; derenkongnj@sina.com
}

Received 21 September 2019; Revised 3 July 2020; Accepted 29 September 2020; Published 16 October 2020

Academic Editor: Yuri S. Karinski

Copyright (C) $2020 \mathrm{Yu}$ Hang et al. This is an open access article distributed under the Creative Commons Attribution License, which permits unrestricted use, distribution, and reproduction in any medium, provided the original work is properly cited.

\begin{abstract}
When a penetrator penetrates a target, security issues such as detonation and deflagration sometimes occur in the embedded explosive under an extreme environment with high overload and severe mechanical shock. Explosives withstand multiple impact stresses with high amplitudes during a multilayer target penetration (MTP) process. Manganin pressure gauges and external dynamic testing systems are common instruments to evaluate explosive safety. However, this method is unsuitable for an MTP experiment where the penetrator flies with a long distance. This article proposes a stress measurement system (SMS) installed in a penetrator for explosive stress detection based on a qualitative analysis for the stress characteristics of the explosive. A highstrength mechanical structure is designed for the SMS to survive in the MTP environment. A low-power management mechanism realized by dual MCUs (STM32 + FPGA) is proposed to reduce the power consumption of the SMS. An experimental investigation is carried out to verify the feasibility of the measurement system designed in this paper. An MTP numerical simulation is carried out to reveal the characteristics of stress occurring and propagating in the explosive. An MTP experiment is conducted and the impact stresses on the explosive surface are measured by the fabricated SMS prototypes. The measurement results are consistent with the simulation results, which indicate that the prototypes have the abilities of high-precision data acquisition and storage in the MTP experiment.
\end{abstract}

\section{Introduction}

Penetrators have become the primary weapons for destroying fortifications in modern high-tech wars $[1,2]$. Carrying embedded explosives, a penetrator usually passes through multiple protective layers of fortification with substantial kinetic energy and then ignites the explosive to cause precise destruction as soon as it arrives at a preset depth of the fortification [3]. During an MTP process, repeated impacts applied to the ammunition give rise to mechanical damage for the explosive. Thus "hot spots" are formed in a tiny space of the explosive and cause vigorous explosions for the penetrator [4-7]. The shock-to-detonation (STD) transition significantly weakens the weapon's damage efficiency. Therefore, it has become a hot issue to evaluate explosive safety in a harsh MTP environment.

At present, relative experiments have been designed to simulate impact scenarios for the explosive, such as Susan test and drop-weight test. In Susan test, a projectile carries explosive to hit a steel target at high velocity. The explosive blasts due to the squeeze and nip between the metal surfaces of projectile and the target $[8,9]$. Explosives in drop-weight test are confined to the bottom of a hammer. The hammer is lifted to a preset height and then is released to impact a steel plate $[10,11]$. Susan test and drop-weight test are suitable to simulate a single impact for the explosive but cannot simulate the repetitious stress impacts $[12,13]$ applied to the explosive. During the MTP process, multiple impacts are applied to the explosive successively, and they will propagate through the explosive in the form of stress waves. The amplitude, loading method, and propagation characteristics of the impact stress are essential for the explosive safety evaluation in a penetrator, but they are seldom investigated due to the harsh experiment environment.

Nowadays, manganin pressure gauges and external dynamic testing systems (EDTSs) are commonly used for 
explosive safety measurement. The manganin gauges are usually placed on the explosive surface to measure the shock pressure [11,14-16]. The EDTS consists of individual instruments such as signal conditioner and digital storage oscilloscope, which are placed in a laboratory for data acquisition. EDTSs have proved convenient and reliable for explosive pressure measurement in the laboratory environment. As for a real MTP process, the penetrator flies with a long distance at high velocity. Long cables are needed to connect the pressure gauges to the EDTS, which will complicate the structure of the penetrator and bring unnecessary noise to the EDTS.

In recent years, embedded on-board-recorder (OBR) systems replace the bulky and heavy EDTS to measure physical parameters for the flighting projectiles such as base pressure, impact-induced contact force, and penetration deceleration [17-21]. Powered by batteries, OBR system usually integrates signal conditioning module, data acquisition module, and data storage module in one circuit board with a miniaturized structure. The OBR system can be preinstalled in the cavity of a projectile and operate continuously during a ballistic period, which eliminates the signal noise caused by long cables. Most OBR systems choose high-performance processors and A/D converters for high-precision data acquisitions. However, the electronic components consume much energy and energy shortage issues exist in most battery-powered systems [22]. A low-power-consumption design is essential to increase the service life of the OBR system in a projectile launching application [23].

To date, there has been no particular device to measure the impact stress of the explosive in the MTP process. Based on the OBR technology, this paper proposes a miniature and low-power-consumption stress measurement system (SMS) to solve the problem. In Section 2, the stress characteristics of the explosive are analyzed and the structure of the penetrator utilized for the MTP experiment is outlined. The mechanical structure of the SMS and the operation mechanism of the measurement system are described in Section 3. Section 4 conducts an experimental investigation to evaluate the signal acquisition performance of the measurement system. Besides, an MTP numerical simulation and an MTP experiment based on inert explosive are carried out to verify the function of the developed SMS prototypes. Finally, we conclude the results of the verification experiment and discuss the future for the SMS in Section 5.

\section{Architecture of MTP Experiment}

2.1. Analysis for Stress Characteristics of Explosive in MTP. Figure 1 shows the architecture of the MTP experiment. The MTP experiment consists of a penetrator and five thin concrete targets. The penetrator has an alloy casing filled with polymer-bonded explosives (PBXs). The targets are situated at regular intervals along the flight track of the penetrator. The penetrator penetrates each target successively at high velocity to simulate strikes against fortification.

The stress characteristics of the embedded explosives are closely related to the movement of the penetrator. For a single-layer thin target penetration, the penetrator drills a hole through the target and gets penetration resistance against the moving direction. The penetrator decelerates under the action of the penetration resistance. The explosive moves towards the front of the alloy casing due to its inertia force as well as the casing's constraint. Impact stress is generated at the contact area between the front end of the explosive and the casing; then, it propagates through the explosive in the form of a compression wave. The explosive is compressed [11] and damaged under the action of compression stress. The damage is mainly manifested as the transformation of micropores and air gap defects to the appearance of cracks, resulting in the spallation of the explosive. In addition, the deformation of the explosive under the action of the high compression stress is larger than the deformation of the casing due to the different elastic modulus between the explosive and the casing $[11,24]$. Thus, a tiny gap is formed between the back end of the explosive and the casing. A tensile wave is generated as a result of the compression wave reflected from the free surface of the explosive. Under the action of the tensile wave, the explosive moves towards the rear of the casing and another impact stress is generated on the contact area.

When it comes to the MTP process, the penetrator withstands multiple penetration resistances and the explosive withstands impact stresses at its front-end surface correspondingly. New compression waves are superimposed on the old compression or tensile waves in the explosive, compressing and stretching the explosive repeatedly. Both the impact stresses and the stress waves make the explosive rub and collide with the casing, which will damage the explosive and cause security issues such as explosive detonation and deflagration under the conditions of high-amplitude stress, repetitious impact, and high explosive sensitivity $[11,25]$.

\subsection{Structure of the Penetrator. Manganin pressure gauges} have been widely used to measure shock pressure of explosives in laboratory applications. The manganin gauges are inappropriate for an MTP application because the explosive withstands multiple severe impacts as well as large deformation. Thus, the gauge's thin-film structure and lead wires can be damaged before the end of the experiment. A pressure sensor with high-strength structure is more convenient and reliable for stress measurement in the MTP. Embedding a sensor in the explosive to measure the stress wave inside of the explosive is challenging. However, it is operable to connect the sensor to the mechanical structure of the penetrator and make the sensor's sensitive surface coplanar with the end surface of the explosive. The sensor can record the impact stresses between the explosive and the casing according to the law of action force and reaction force.

Figure 2 shows the structure of the penetrator designed to measure the impact stress of the explosive in the MTP. The penetrator is composed of an alloy casing, castable inert PBXs, and two SMSs named front-end SMS and back-end SMS, respectively. The penetrator has two cabins with different size to contain the explosives. The front-end SMS is installed at the front end of the second cabin to measure the 


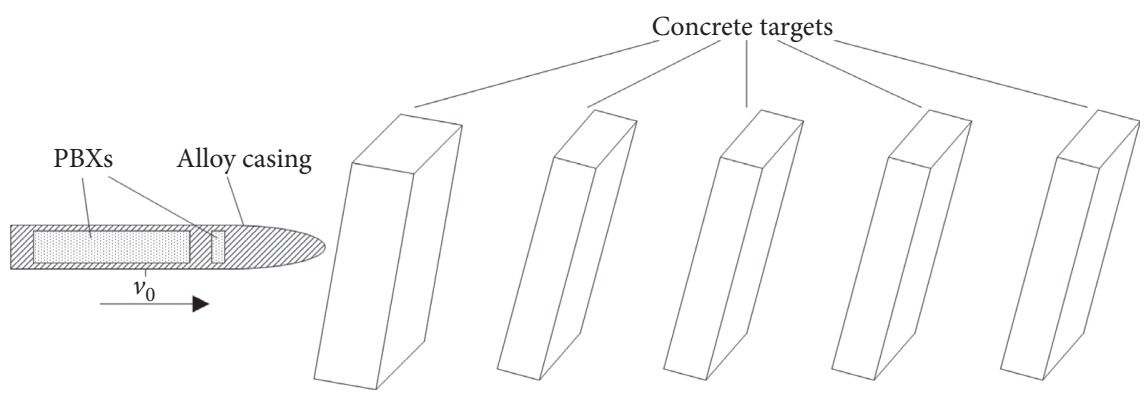

Figure 1: The architecture of the MTP experiment.

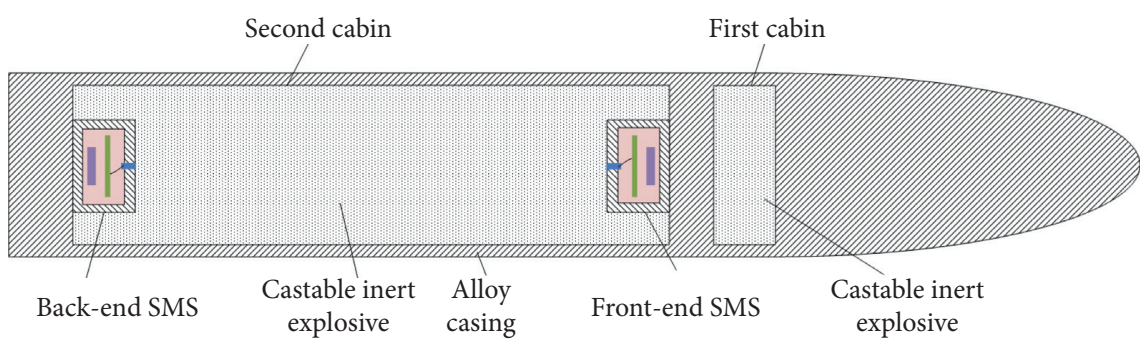

Figure 2: Structure of the penetrator.

stress on the front end of the explosive. The back-end SMS is installed at the back end of the second cabin to measure the stress on the back end. The explosive used for the experiment has low explosive sensitivity, and it is not easy to detonate during the experiment. Thus, the measurement devices can be recycled after the MTP process.

\section{Design of the SMS}

3.1. Structure Design of the SMS. The two SMSs operate continuously when they move along with the penetrator in the MTP experiment. Then, the recorded signals are uploaded to a computer for further analysis after the experiment. A pressure sensor, a data acquisition and record (DAR) circuit, and a battery are fundamental components for the SMS. Powered by the battery, the pressure sensor can convert the dynamic stress into an analog signal and the DAR circuit has the function of data acquisition and storage. A high-strength mechanical structure of the SMS can protect the electronic components from the high overload and severe impact during the experiment.

As is shown in Figure 3, the structure of the SMS mainly consists of a housing, an end cover, a pressure sensor, a DAR circuit board, a polymer lithium-ion battery, and rubber cushions. The housing is made of 7075 heat-treated aluminum alloy with density of $2800 \mathrm{~kg} / \mathrm{m}^{3}$ and yield strength of $500 \mathrm{MPa}$, which provides a lightweight and high-strength protection for the other components of the SMS. The housing is rigidly connected to the penetrator through the thread. The end cover, which directly contacts the explosive, can seal the housing and provide a mounting hole for the sensor. The end cover is made of titanium alloy with a high yield strength of $700 \mathrm{MPa}$, aiming at improving shear resistance when it withstands impact stress from the explosive.
A Kistler 217C pressure sensor is chosen to measure the impact stress of the explosive. The sensor has an eigenfrequency of $200 \mathrm{kHz}$ and a measuring range of $500 \mathrm{MPa}$. The sensor's fast ( 2 microseconds) rise time along with the excellent accuracy and repeatability [26] makes it well suited for dynamic impact stress measurement in the MTP. The sensor has a high-strength metal shell and can be installed in the mounting hole of the end cover. The sensitive surface of the sensor, the outside surface of the end cover, and the end surface of the explosive are coplanar for the purpose of recording the impact stress of the explosive correctly.

Both the DAR circuit board and the polymer lithium-ion battery are placed in the cavity of the housing. The rubber cushions are stuck on the internal surface of the casing. The spare space of the casing is filled with polyurethane foam material to absorb the stress wave propagating to the circuit board and the battery. Under the protection of the mechanical structure, the DAR circuit will operate reliably in a high-g penetration environment.

3.2. Design of the DAR Circuit. The experimental procedure mainly consists of five steps: (1) installing the front-end SMS; (2) pouring the castable inert explosive into the alloy casing of the penetrator and installing the back-end SMS; (3) waiting for the explosive to cool down and then transporting the penetrator to the experimental field; (4) launching the penetrator; (5) MTP process. The third step usually lasts for days while the fifth step only lasts for 200 milliseconds. In order to guarantee the structural integrity of the penetrator, the SMSs are mechanically isolated from the environment outside of the penetrator. Therefore, the DAR circuits need to be powered on before the SMSs are connected to the penetrator and then spend a standby time of several days 


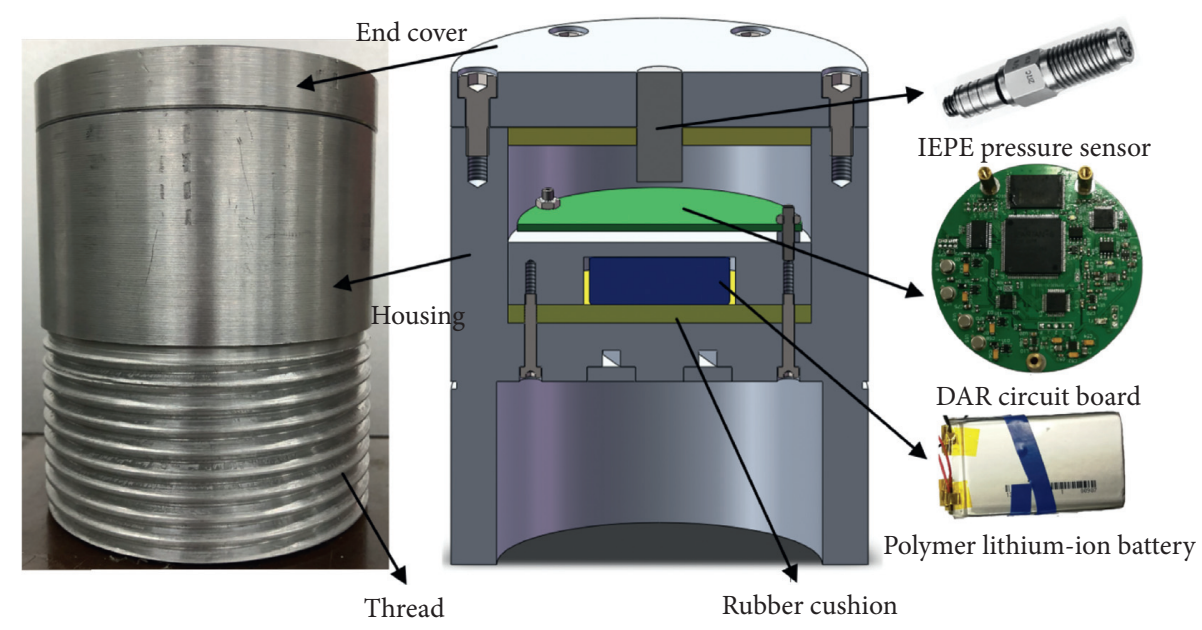

FIgURE 3: Structure of the SMS.

until the experiment begins. The DAR circuits should identify and capture the impact stress signal automatically during the MTP. The performance indexes which the DAR circuits should meet are listed in Table 1.

There are three principles to design a miniature and lowpower-consumption SMS: first, simplifying the function modules of the DAR; second, choosing the electronic components with small packages; third, introducing a lowpower-operation mechanism and reducing the volume of the battery. Based on these principles, the DAR circuit includes the signal acquisition (SA) module and the low-power management (LPM) module. The detailed schematic structure of the DAR circuit is shown in Figure 4(a), and the relationship between the experimental procedure and the DAR operation state is illustrated in Figure 4(b).

3.2.1. Signal Acquisition Module. The SA module mainly achieves sensor driving, signal conditioning, data acquisition, and data storage. The SA module mainly consists of a power supply unit, a filter, an analog-to-digital converter (ADC), a data storage unit, a USB driver, and a processing core. Based on the Integral Electronic Piezoelectric Excitation (IEPE) technology, the pressure sensor can convert a stress signal into a voltage signal. A $4 \mathrm{~mA}$ constant current source is necessary to drive the pressure sensor. The current source chosen here is LM134 from Analog Devices, Inc. (ADI), which can be driven by an external $24 \mathrm{~V}$ input voltage source. The $24 \mathrm{~V}$ voltage is generated by a low-power DCDC converter TPS61041 from Texas Instruments, Inc. (TI). The output signal of the IEPE sensor is superposed with a bias voltage of $11 \mathrm{~V}$; thus, a simple passive RC high-pass filter is used to eliminate the DC bias voltage.

A 12 bit parallel ADC MAX1309 from Maxim Integrated Products, Inc. is chosen to convert the voltage signal from the signal conditioning unit to the digital signal. The maximum throughput of the ADC is $1075 \mathrm{kSPS}$, which is adequate for dynamic stress acquisition. The data storage unit consists of an FM25V10 Ferroelectric RAM (FRAM) from Cypress Semiconductors Corp. and a K9W8G08U1M NAND FLASH chip from Samsung Semiconductor Inc. The
FRAM is a 1 Mbit nonvolatile memory logically organized as $128 \mathrm{~K} \times 8$. The chip has a read and write speed of $0.2 \mu$ s/byte and it does not need an erase operation before a write operation. The FLASH has a storage capacity of $512 \mathrm{MB}$ and can be programmed by page. Its typical page programming time is $300 \mu \mathrm{s}$ and the data must be erased before programming. An FT245 bidirectional data transfer chip from Future Technology Devices International Ltd. is used as the USB driver for data interaction between the PC and the SA module.

A Xilinx Spartan series FPGA is selected as the processing core for the SA module, aiming at controlling the whole data acquisition and storage process. The block diagram of the logic function in the FPGA is shown in Figure 5(a). A silicon oscillator chip LTC6905 from ADI supplies a $50 \mathrm{MHz}$ clock source to the FPGA. Compared with traditional crystal oscillators, the LTC6905 has a miniature size and is quite suitable for a high overload environment. The external clock source is divided into four internal sources by the Phase Locked Loop (PLL) in the FPGA. These internal sources supply clocks for the top-level module, the ADC controller, USB communication controller, and storage allocator.

The data acquisition time is set to $200 \mathrm{~ms}$ to cover the whole MTP process. An internal trigger mechanism, which is realized by the trigger detector module in the FPGA, is adopted to capture the starting point for the data acquisition period. Figure 5(b) shows the state transition diagram in the FPGA. The main logic in the FPGA alternates in seven states, namely, FLASH reading, preprocessing, cyclic presampling, effective data acquisition, standby, data uploaded, and FLASH reset.

After the SA unit is powered on, the FPGA turns to the FLASH reading state and reads the status information stored in the FLASH. The "FLASH empty" information indicates that the FLASH can be written in; then, the FPGA executes a block erase operation to erase the FLASH under the preprocessing state. The FPGA transfers to the cyclic presampling state after the erase operation is done. In this state, the FPGA compares an A/D conversion result with a preset 
TABle 1: Performance indexes of the DAR circuit.

\begin{tabular}{lccccc}
\hline Index & Data resolution (bit) & Sample rate $(\mathrm{kHz})$ & Date length $(\mathrm{ms})$ & Standby power $(\mathrm{mW})$ & Standby time $($ day) \\
\hline Value & 12 & 500 & 200 & $<1$ & 15 \\
\hline
\end{tabular}

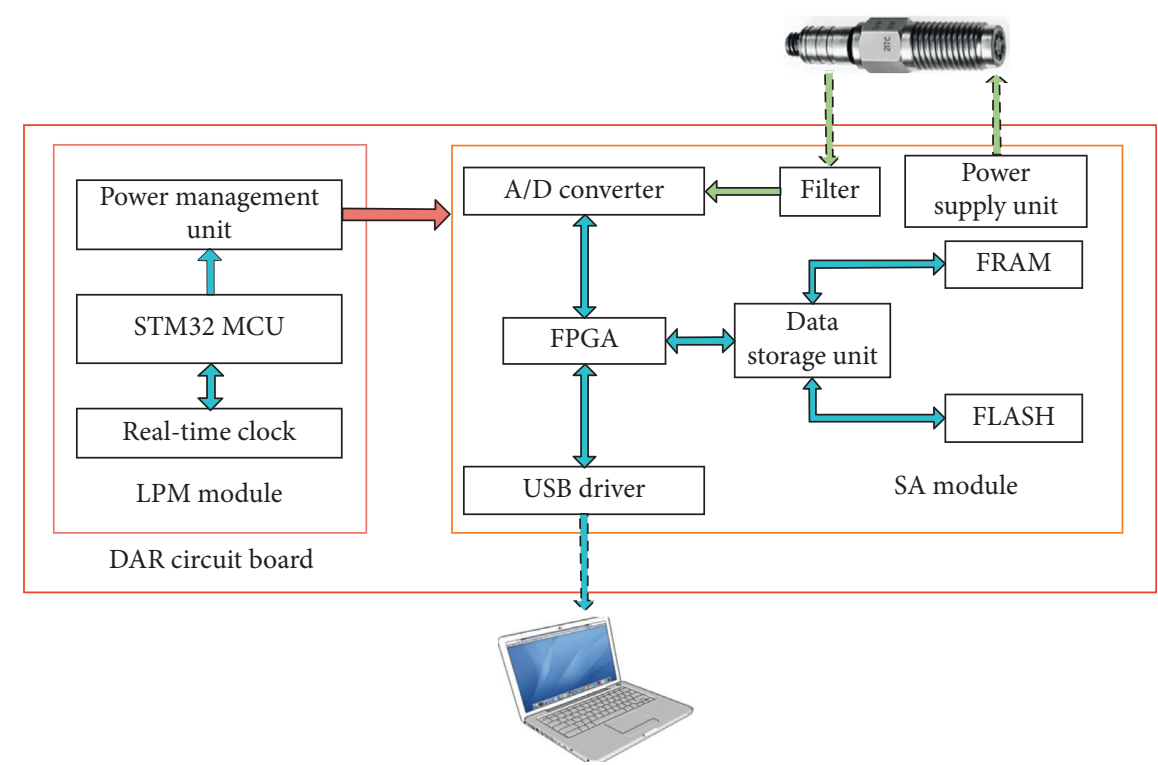

(a)

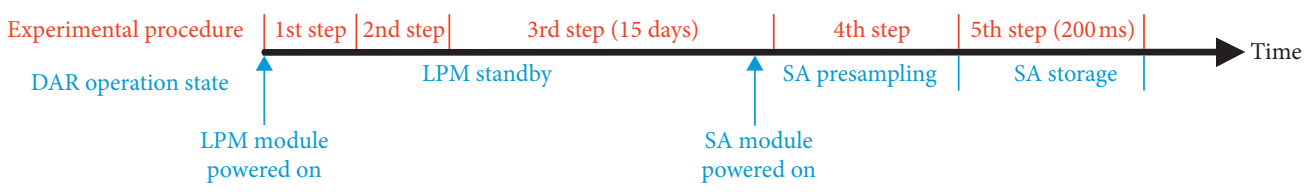

(b)

FIgURE 4: DAR circuit. (a) Schematic structure of the DAR circuit. (b) Relationship between the experimental procedure and the DAR operation state.

trigger threshold. If the conversion result does not exceed the trigger threshold, the FPGA writes the result into the FRAM and executes another comparison. The FRAM performs sequential writes from its first address to the last, and then the counter in the FRAM will roll over to the first address again. If a conversion result exceeds the trigger threshold, it means that the sensor has identified the penetration process. The FPGA will switch to the effective signal acquisition state from the cyclic presampling state immediately. The ADC keeps operating for $200 \mathrm{~ms}$, and the conversion results are stored in the FLASH immediately. Then, the FPGA disables the ADC and writes the "FLASH full" information into the FLASH. The FPGA switches to the standby state if the status information in the FLASH is "FLASH full." In the standby state, the top-level module of FPGA receives and analyzes commands from the PC controller. If a "data uploaded" command is received, the FPGA uploads messages recorded in the data storage to the PC controller via the USB data transfer unit. After that, the PC controller transmits a "FLASH reset" command to the FLASH, and the FPGA sets the "FLASH empty" information to the FLASH again, enabling another data acquisition operation for the SA unit. The logic transition mechanism can prevent the SA unit from erasing the effective data when it is reenergized.

3.2.2. Low-Power Management Module. The chips such as FPGA, ADC, and FLASH which are used in the SA module consume electric energy to achieve high performance. According to the DAR operation state illustrated in Figure 4(b), the LPM module is powered on at the beginning of the experimental procedure and powers the SA module. The LPM module mainly consists of an MCU unit, a realtime clock (RTC) chip, and a power management unit.

The core of the MCU unit is STM32F103CBT6 from STMicroelectronics, Inc. The STM32 has abundant communication interfaces and supports interface protocols such as I2C, SPI, UART, and USB. Three low-power modes and relative wake-up mechanisms are supported to achieve the compromise between low-power consumption and short start-up time for the STM32. The RTC chip utilized is DS3232 M from Maxim. The DS3232 M supplies a complete clock calendar and two time-of-day alarms.

In the power management unit, the utilized DC/DC converter chips supply power for the SA module under the 


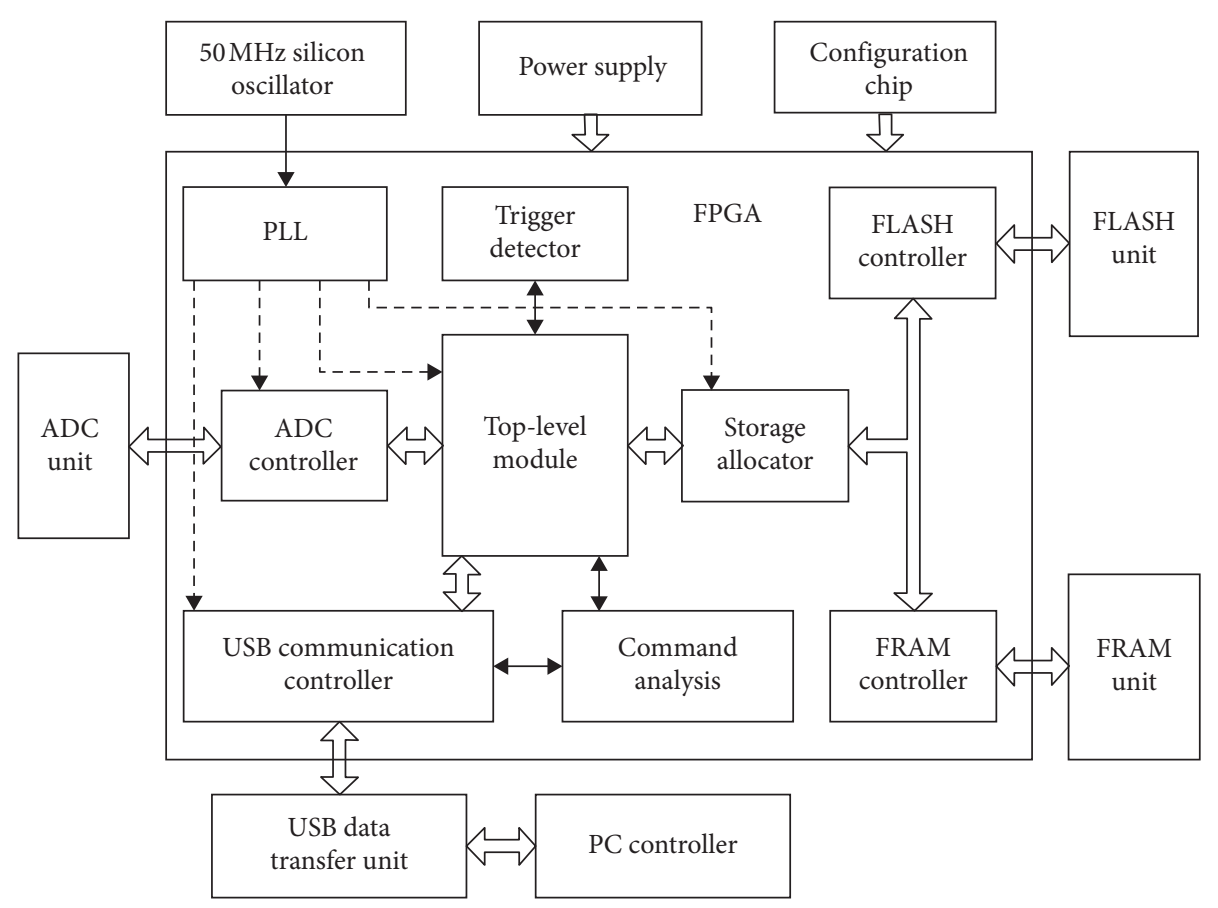

(a)

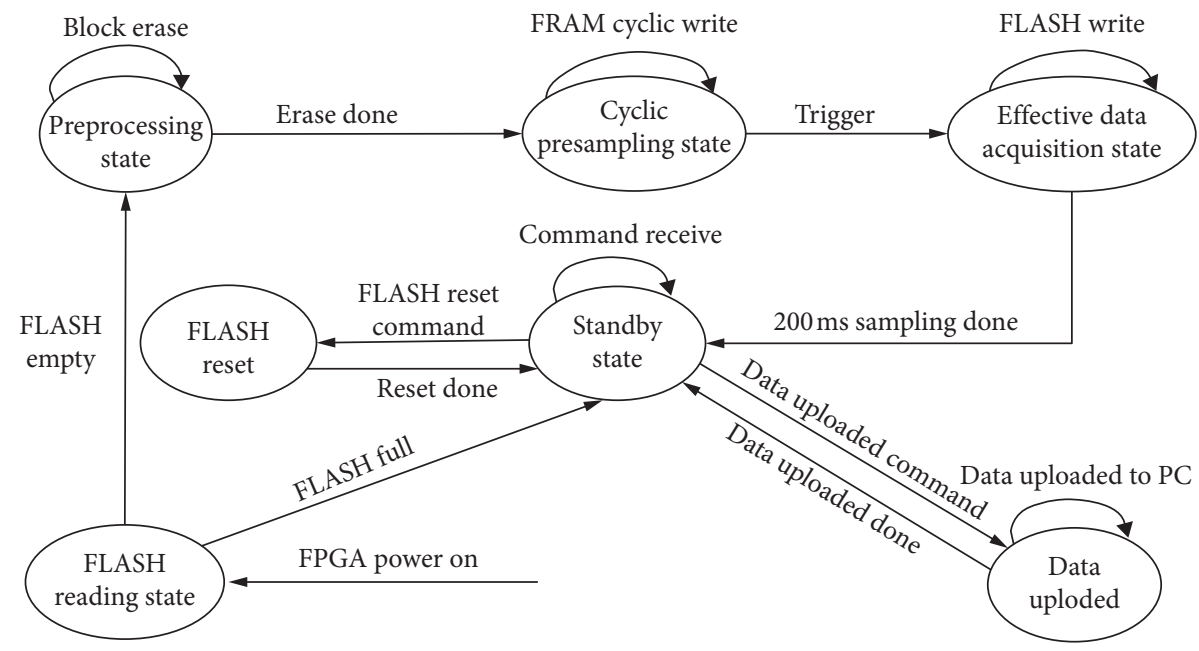

(b)

FIgUre 5: FPGA. (a) Block diagram of logic function. (b) State transition diagram.

control of the STM32. Among them, LT3532 from ADI transforms the $3.7 \mathrm{~V}$ voltage from the lithium-ion battery to a $3.3 \mathrm{~V}$ at $500 \mathrm{~mA}$ output, and ADP1713-1.2 from ADI transforms the $3.7 \mathrm{~V}$ voltage to a $1.2 \mathrm{~V}$ voltage. If the STM32 pulls the enable pins of the DC/DC converter chips to a low level, the DC/DC converter will be forced into shutdown mode with a supply current less than $1 \mu \mathrm{A}$, thus disabling the SA module from operating.

Figure 6 shows the working mechanism of the LPM module. After the DAR circuit is powered on, the STM32 pulls down the enable pins of the DC/DC converters to disable the SA unit. Then, the STM32 initializes the RTC chip by writing the current time information into the timekeeping register and setting the time-of-date alarm with the prospective time information of the experiment. Afterward, the STM32 executes a sleep state with a supply current of $14 \mu \mathrm{A}$, and the RTC automatically changes the current time values in its timekeeping register at an operating current of $100 \mu \mathrm{A}$. The RTC provides an interrupt signal to wake up the STM32 from its sleep state as soon as the current time value matches the prospective time information. Then, the STM32 pulls up the enable pins to activate the DC/DC converter and the SA unit will be powered on.

The average operating power of the LPM module and the SA module is $0.7 \mathrm{~mW}$ and $1.1 \mathrm{~W}$, respectively. If the LPM standby state lasts for 15 days and the SA presampling state lasts for 2 hours, the total power consumption 


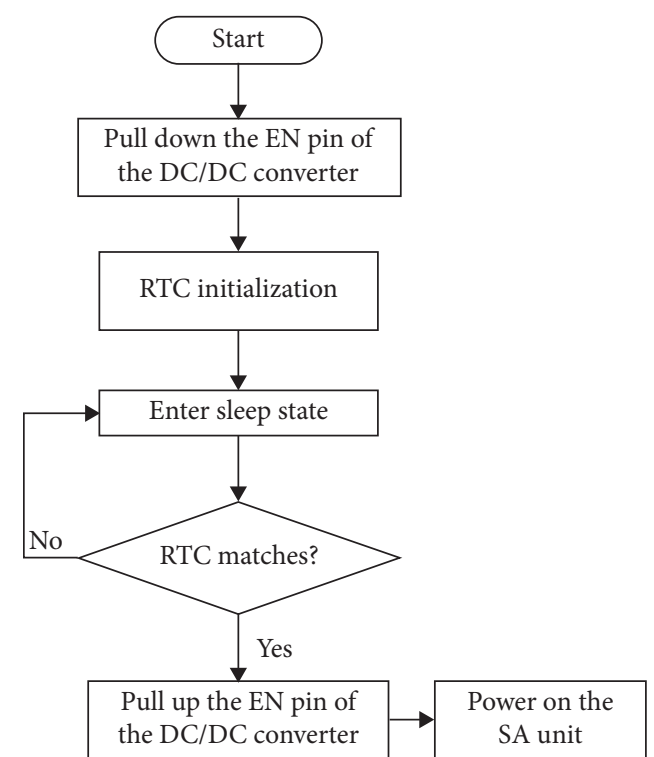

FIGURE 6: Working mechanism of the standby mode for the LPM unit.

of the system is $2.452 \mathrm{Wh}$. A battery with a nominal capacity of $7.4 \mathrm{Wh}(3.7 \mathrm{~V}, 2 \mathrm{Ah})$ is sufficient for the DAR circuit.

\section{Verification of the SMS System}

4.1. Verification of the Measurement System. An experimental investigation is carried out to evaluate the signal acquisition performance of the designed measurement system. As shown in Figure 7, the signal acquisition experiment system consists of an IEPE pressure sensor, a DAR circuit, a digital storage oscilloscope (type ROGEL-DS2102 from RIGOL Technologies Co., Ltd), an impact hammer (type LC-02A from Sinocera Piezotronics, Inc.), and a PC controller. The sensor is installed in the mounting hole of a steel plate. Multiple impacts are applied to the sensitive surface of the sensor within $200 \mathrm{~ms}$ by the impact hammer which has a nylon hammerhead. The output signal of the sensor is filtered by the high-pass filter of the DAR circuit. The output voltage signal of the filter is acquired by the oscilloscope and the DAR circuit, respectively. The sample rate of the oscilloscope is $500 \mathrm{kHz}$, which is equal to the sample rate of the DAR circuit.

Figure 8 shows the voltage versus time curves recorded by the oscilloscope and the DAR circuit. The impact hammer induces six impact pulses. The peak amplitudes extracted from the oscilloscope are $1.57 \mathrm{~V}, 1.33 \mathrm{~V}, 0.67 \mathrm{~V}, 0.47 \mathrm{~V}$, $0.27 \mathrm{~V}$, and $0.13 \mathrm{~V}$. The peak amplitudes recorded by the DAR circuit are $1.545 \mathrm{~V}, 1.31 \mathrm{~V}, 0.664 \mathrm{~V}, 0.4702 \mathrm{~V}, 0.2602 \mathrm{~V}$, and $0.1383 \mathrm{~V}$. Moreover, the positions of each pulse are $20.35 \mathrm{~ms}, 53.9 \mathrm{~ms}, 69.35 \mathrm{~ms}, 79.1 \mathrm{~ms}, 87.19 \mathrm{~ms}$, and $92.91 \mathrm{~ms}$ in the oscilloscope and are $20.35 \mathrm{~ms}, 53.87 \mathrm{~ms}, 69.34 \mathrm{~ms}$, $79.1 \mathrm{~ms}, 87.24 \mathrm{~ms}$, and $92.92 \mathrm{~ms}$ in the DAR circuit. The signal acquisition performance of the DAR circuit is consistent with the oscilloscope.
4.2. MTP Numerical Simulation and Discussion. An MTP numerical simulation is conducted by using ANSYS LSDYNA explicit dynamic finite element software. Based on the architecture of MTP in Figures 1 and 2, the alloy casing of the penetrator has a diameter of $0.3 \mathrm{~m}$ and a length of $2.5 \mathrm{~m}$. The two cabins of the penetrator are $0.26 \mathrm{~m}$ in diameter. The lengths of the first and second cabins are $0.1 \mathrm{~m}$ and $1.4 \mathrm{~m}$, respectively. The first concrete target is $3 \mathrm{~m} \times 3 \mathrm{~m} \times 0.3 \mathrm{~m}$ in size and other targets are $3 \mathrm{~m} \times 3 \mathrm{~m} \times 0.18 \mathrm{~m}$ in size. The distance between the adjacent targets is $3 \mathrm{~m}$, and the incident angle for the oblique penetration model is $10^{\circ}$. Figure 9 shows the half-symmetry finite element model of the MTP based on high-quality eight-node 3D solid elements.

The micromechanics of the explosive such as particle friction and void collapse are ignored to simplify the numerical calculation. The dynamic mechanical properties from macrolevel are discussed in the simulation work. The constitutive model for the explosive and the casing is kinematic hardening_plasticity. A Johnson_Holmquist_Concrete material constitutive model is used for the concrete. The utilized material parameters are shown in Table $2[24,27,28]$ and Table 3 [29, 30].

The eroding_surface_to_surface algorithm is used to simulate the contact behavior between the casing and the concrete target during the MTP. The automatic_surface_to_surface algorithm is adopted to simulate the contact behavior between the casing and the explosive. The normal constraint is applied on the symmetry plane of the finite element model to get reasonable simulation results. The initial distance between projectile and target is set as $22 \mathrm{~m}$. A half-sine pressure is loaded on the base of the penetrator to simulate the launching process and enable the penetrator to reach an initial velocity of $800 \mathrm{~m} / \mathrm{s}$ before penetrating the first target. The simulation model is solved with LSDYNA solver. Figure 10(a) shows six elements distributed along an axial path of the penetrator. E1 and E4 are located at the front end and back end of the explosive, and E2 and E3 are located inside the explosive. The axial stress curves of E1, E2, E3, and E4 are plotted in Figure 10(b)-10(e), respectively. E1P and E4P are located at the end surface of the casing next to E1 and E4. Figure 10(b) and 10(e) also illustrate the axial stress curves of E1P and E4P, aiming at studying whether the installation method of the pressure sensor is reasonable. The start points of the curves are set to $0 \mathrm{~ms}$, which means that the penetrator starts to penetrate the first target.

A compressive stress pulse with amplitude of 98.2 $\mathrm{MPa}$ at $0.63 \mathrm{~ms}$ is shown in Figure 10(b). It is generated because the explosive impacts the casing after the penetrator penetrates the first target plate. The stress propagates in the explosive in the form of a compressive wave, which causes the compressive stress disturbance in E2 at $0.9 \mathrm{~ms}$ and E3 at $1.215 \mathrm{~ms}$. The explosive is compressed by the stress wave and separated from the casing at the back end of the second cabin. The separation process is shown in Figure 10(f). A tensile stress is generated after the first compression wave is reflected from the free back end surface of the explosive. The tensile wave is superimposed onto the compressive wave at $1.53 \mathrm{~ms}$, leading 


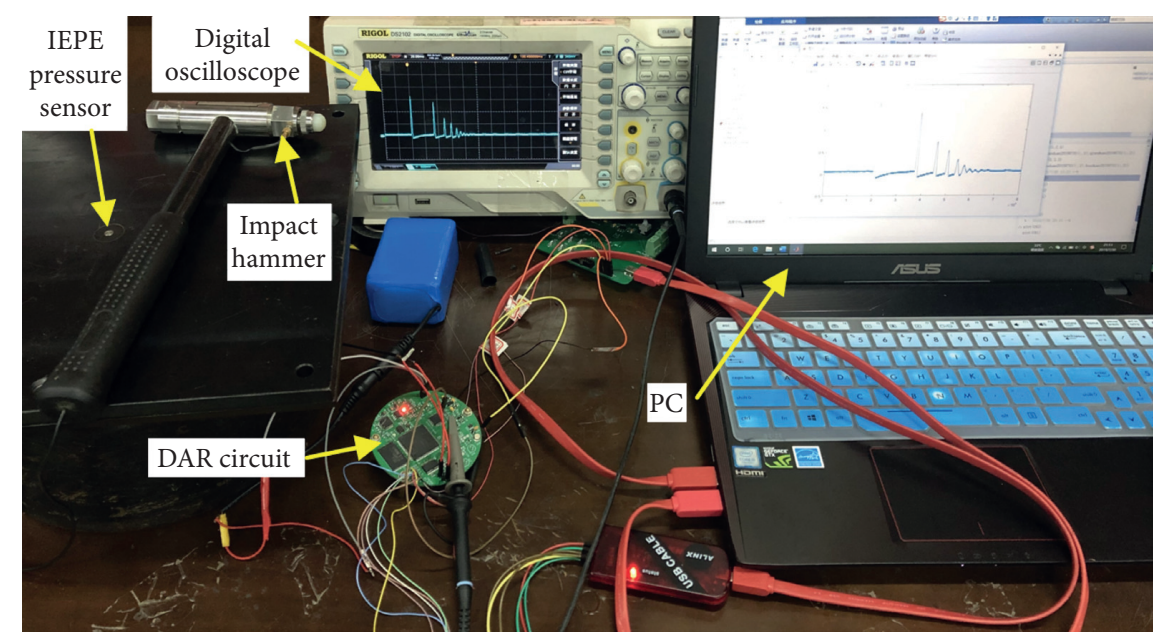

FIgURE 7: Signal acquisition experiment system.

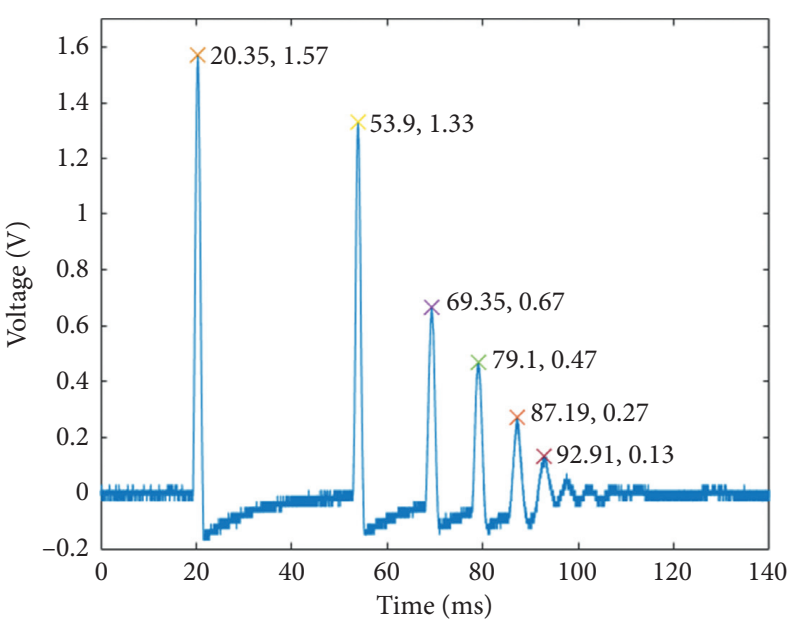

(a)

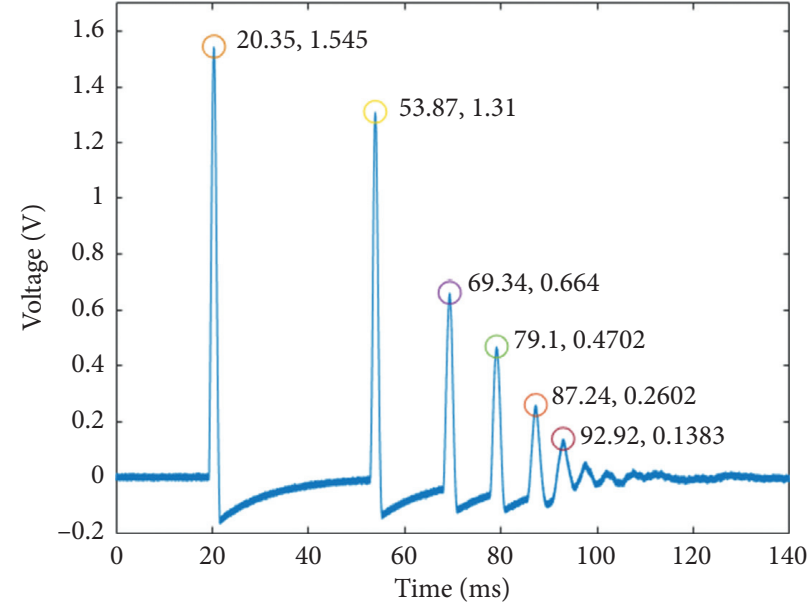

(b)

FIGURE 8: Voltage versus time curves. (a) Voltage signal acquired by the oscilloscope. (b) Voltage signal acquired by the DAR circuit.
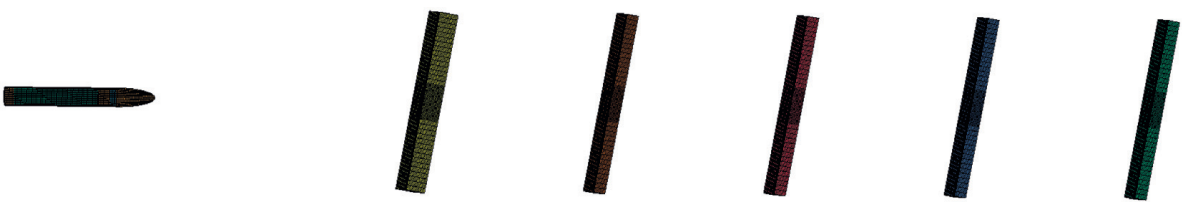

Figure 9: Finite element model.

to a zero stress of E4. Under the action of the forward tensile wave, the explosive impacts the rear face of the casing and a new compression stress pulse is formed at $3.12 \mathrm{~ms}$ of $\mathrm{E} 4$, which is shown in Figure 10(e).

When the penetrator penetrates a concrete target, a new impact stress pulse is generated on the contact area between the explosive and the casing. The impact stress parts in the explosive element $\mathrm{E} 1$ have five dominant peaks with values of $98.2 \mathrm{MPa}$ at $0.63 \mathrm{~ms}, 91.51 \mathrm{MPa}$ at $4.41 \mathrm{~ms}, 92.26 \mathrm{MPa}$ at $8.235 \mathrm{~ms}, 92.12 \mathrm{MPa}$ at $11.99 \mathrm{~ms}$, and $91.73 \mathrm{MPa}$ at $15.91 \mathrm{~ms}$.
The explosive impacts the rear of the casing due to the propagation of these stress waves, and impact stresses are generated at $3.12 \mathrm{~ms}, 7.447 \mathrm{~ms}, 10.98 \mathrm{~ms}, 14.98 \mathrm{~ms}$, and $17.73 \mathrm{~ms}$ in Figure 10(e). The old and the new stress waves propagate through the explosive, are superimposed in the explosive, and are reflected from the free surface of the explosive. Thus, additional impact stresses occur on the end surface of the explosive when the penetrator flies between two concrete targets, such as the pulse at $5.85 \mathrm{~ms}$ in Figure 10(b) and the pulse at $6.188 \mathrm{~ms}$ in Figure 10(e). The 


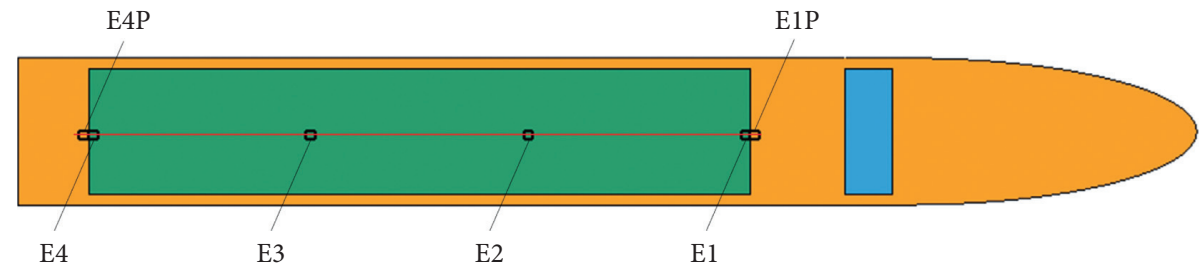

(a)

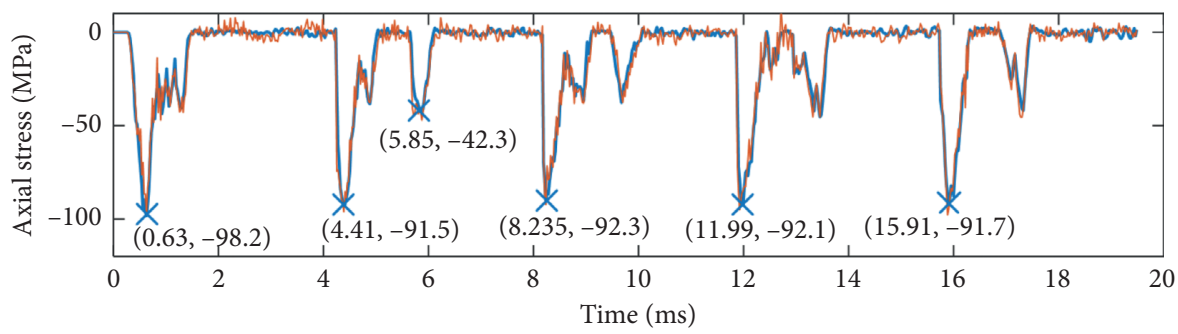

- E1

(b)

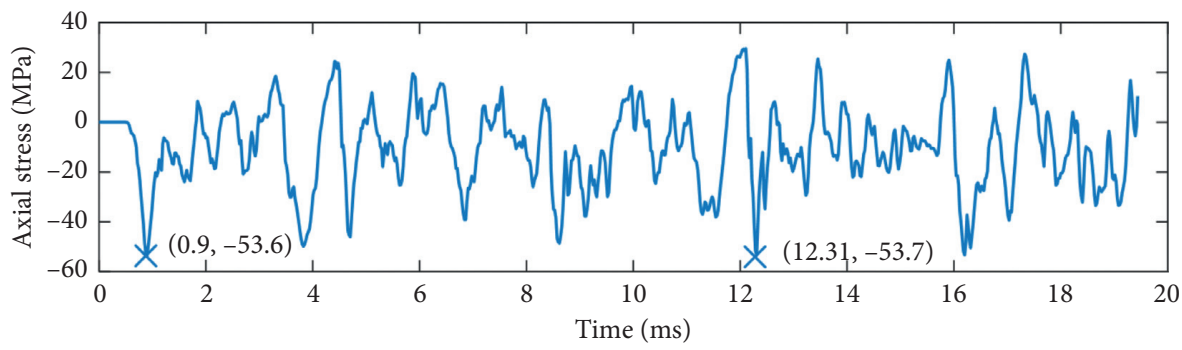

- E2

(c)

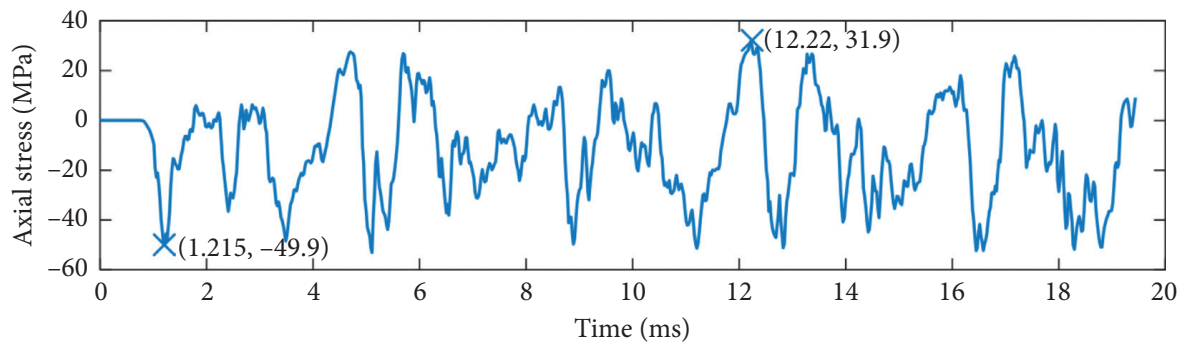

- E3

(d)

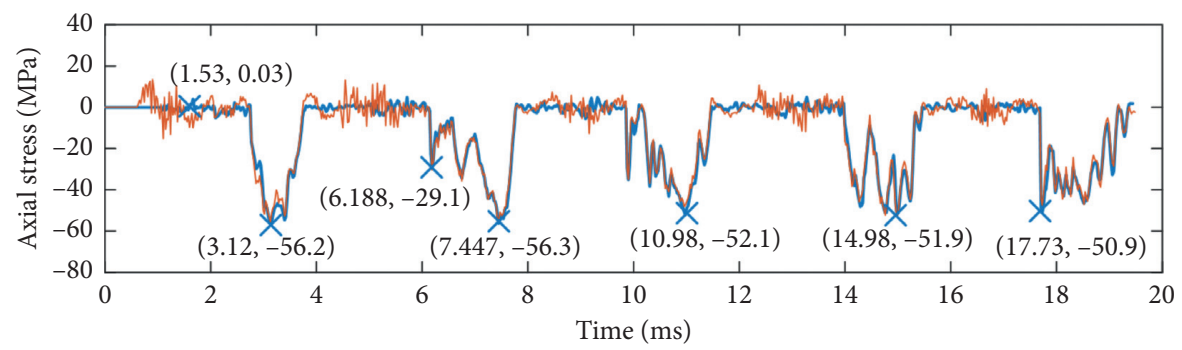

- E4

- E4P

(e)

FIgURE 10: Continued. 

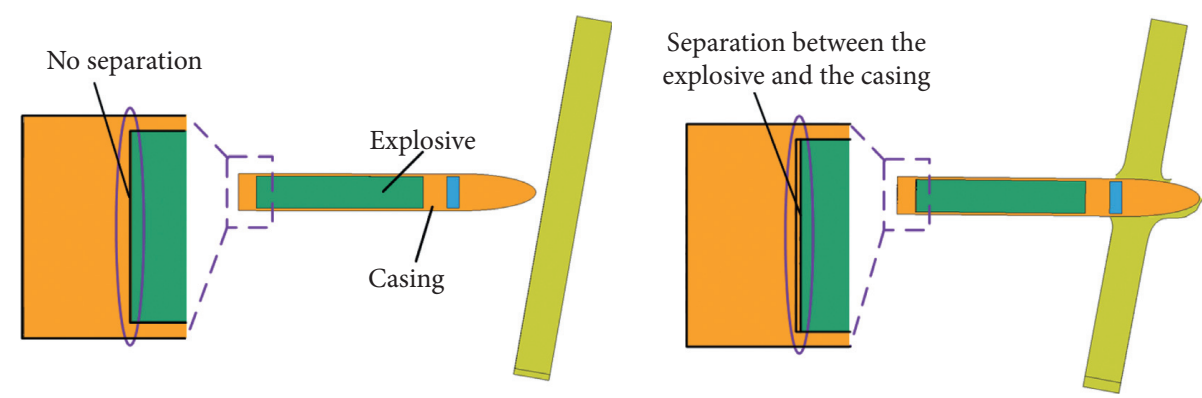

(f)

Figure 10: Simulation results. (a) Elements distribution; (b) axial stress curves for E1 and E1P; (c) axial stress curves for E2; (d) axial stress curves for E3; (e) axial stress curves for E4 and E4P; (f) separation between the explosive and the casing.

TABLe 2: Material parameters of the explosive and the casing.

\begin{tabular}{lcccccc}
\hline & $\rho\left(\mathrm{g} / \mathrm{cm}^{3}\right)$ & $E(\mathrm{GPa})$ & $\nu$ & $\sigma_{\mathrm{S}}(\mathrm{MPa})$ & $E_{t}(\mathrm{GPa})$ & \\
\hline Explosive & 1.8 & 5.4 & 0.31 & 10 & 2.08 & 0.2 \\
Projectile & 7.83 & 210 & 0.28 & 1275 & 2.1 & 1 \\
\hline
\end{tabular}

TABLE 3: Material parameters of the concrete target.

\begin{tabular}{lcccccc}
\hline$\rho\left(\mathrm{g} / \mathrm{cm}^{3}\right)$ & $G(\mathrm{GPa})$ & $\mathrm{A}$ & $\mathrm{B}$ & $\mathrm{C}$ & $N$ & $\mathrm{FC}(\mathrm{MPa})$ \\
2.625 & 14.86 & 0.79 & 1.6 & 0.007 & $\mu$ & $P_{\mathrm{L}}(\mathrm{GPa})$ \\
$\mathrm{T}(\mathrm{MPa})$ & $\varepsilon_{f} \mathrm{~min}$ & $\mathrm{~s}_{\mathrm{f}} \max$ & $P_{C}(\mathrm{GPa})$ & $\mu_{C}$ & 1.1 & \\
4 & 0.01 & 7 & 0.02 & 0.001 & $\mu_{L}$ \\
$D_{1}$ & $D_{2}$ & $K_{1}(\mathrm{GPa})$ & $K_{2}(\mathrm{GPa})$ & $K_{3}(\mathrm{GPa})$ & \\
0.04 & 1 & 85 & -171 & 208 & \\
\hline
\end{tabular}

stress curves of E2 and E3 present negative and positive waveforms, which indicate that both compression wave and tensile wave propagate in the explosive. The maximum value of the compressive stresses in E2 and E3 is $53.7 \mathrm{MPa}$ and the maximum value of the tensile stresses is $31.9 \mathrm{MPa}$.

The correlation coefficient of E1 and E1P in Figure 10(b) is $97.41 \%$, and the correlation coefficient of E4 and E4P in Figure $10(\mathrm{e})$ is $97.02 \%$. The adjoining explosive element and casing element have similar waveforms at their impact stress parts. The maximum crest error between the adjoining elements is $4.05 \mathrm{MPa}$ at $15.91 \mathrm{~ms}$ in Figure 10 (b). The error is $4.13 \%$ of the maximum stress which occurs in the explosive, indicating that the pressure sensor coplanar with the explosive can record the impact stresses generated on the explosive surface correctly. The stresses between the adjoining elements are somewhat different at the nonimpact stress parts because the stress waves have different propagation velocity and amplitude in two materials which have different shock impedances as well as dimensions. However, the amplitudes at the nonimpact stress parts approach zero; thus, these differences can be ignored.

Figure 11 shows the axial stress contours of the explosive. Figure 11(a) depicts that the compression stress is only distributed in the forepart of the explosive at $0.5 \mathrm{~ms}$, which illustrates a clear progression of the first impact stress propagating through the explosive. Figure 11(b) depicts the stress distribution at $4.7 \mathrm{~ms}$ after the penetrator penetrates the second target. The compression waves exist in the forepart of the explosive, and the tensile waves exist in the rear, showing that the explosive has different stress characteristics at different positions due to the propagation, reflection, and superimposition of the stress waves.

4.3. MTP Experiment and Discussion. An MTP experiment is conducted to measure the impact stress of the explosive. The penetrator is accelerated by a recoilless gun and achieves an initial penetration velocity of $800 \mathrm{~m} / \mathrm{s}$. Figure 12 shows the installation structure of the front-end SMS prototype and five thin concrete targets penetrated after the MTP experiment.

The front-end stress curve and the back-end stress curve of the explosive recorded in the SMSs are shown in Figure 13. Five dominant stress pulses are extracted from the front-end stress curve. Each stress pulse increases and then decreases, reflecting the impact between the explosive and the casing after a single penetration. Five dominant stress pulses are also extracted from the back-end stress curve, and they reflect the procedures that the explosive impacts the rear of the casing.

Table 4 lists the peak value of the stress curves from the MTP experiment as well as the MTP simulation. The last two columns of Table 4 list the calculated relative errors between simulation and experiment. The maximum relative error of the front-end stress curve is $5.02 \%$ and the minimum relative error is $0.54 \%$. The maximum back-end relative error is $4.72 \%$ 


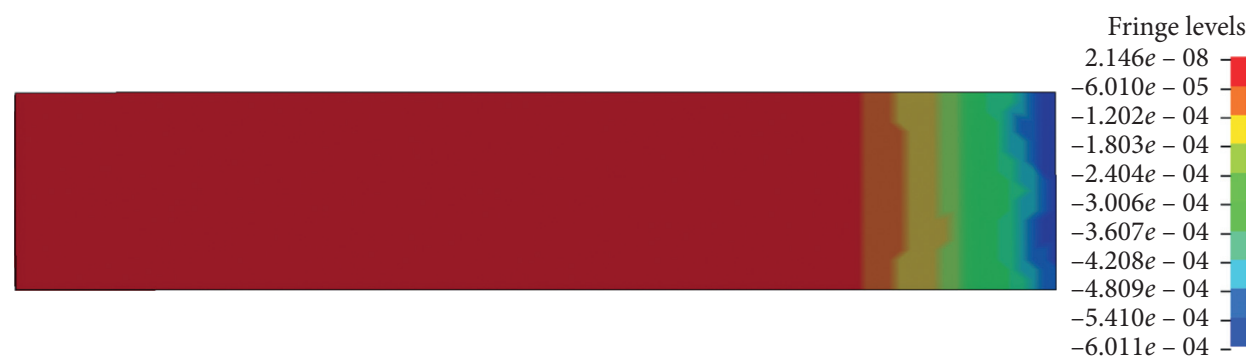

(a)

Fringe levels $3.293 e-04$ $2.202 e-04$

$1.110 e-04$

$1.803 e-06-$

$-1.073 e-04-$

$-2.165 e-04$

$-3.257 e-04-$

$-4.349 e-04$

$-5.440 e-04$

$-6.532 e-04$

$-7.624 e-04$

(b)

Figure 11: Stress contour. (a) $t=0.5 \mathrm{~ms}$; (b) $t=4.7 \mathrm{~ms}$.

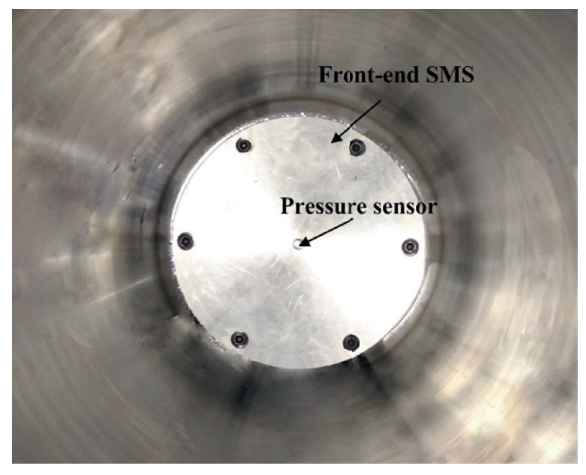

(a)

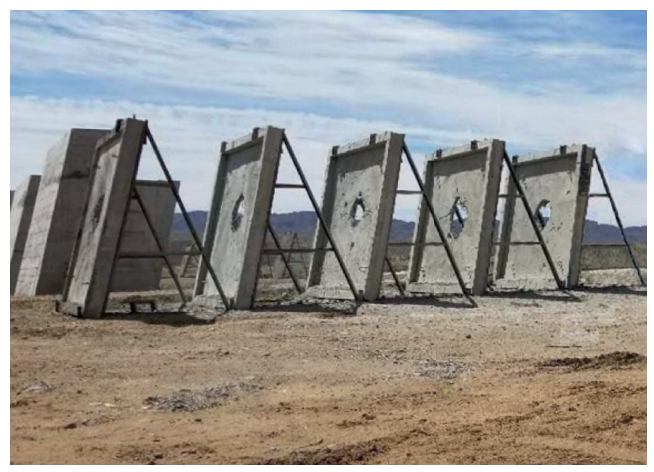

(b)

FIgURE 12: The MTP experiment. (a) Installation structure of the front-end SMS prototype. (b) Concrete targets.

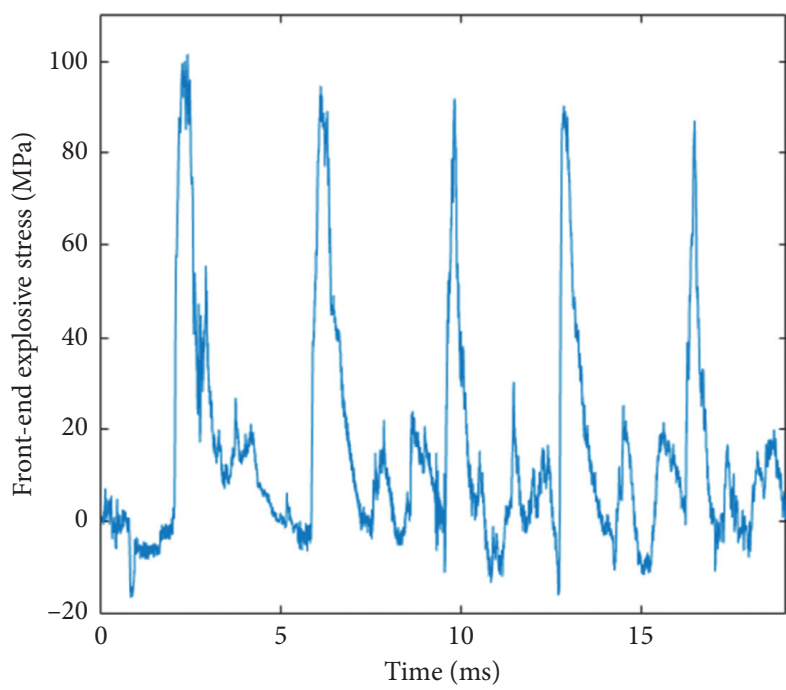

(a)

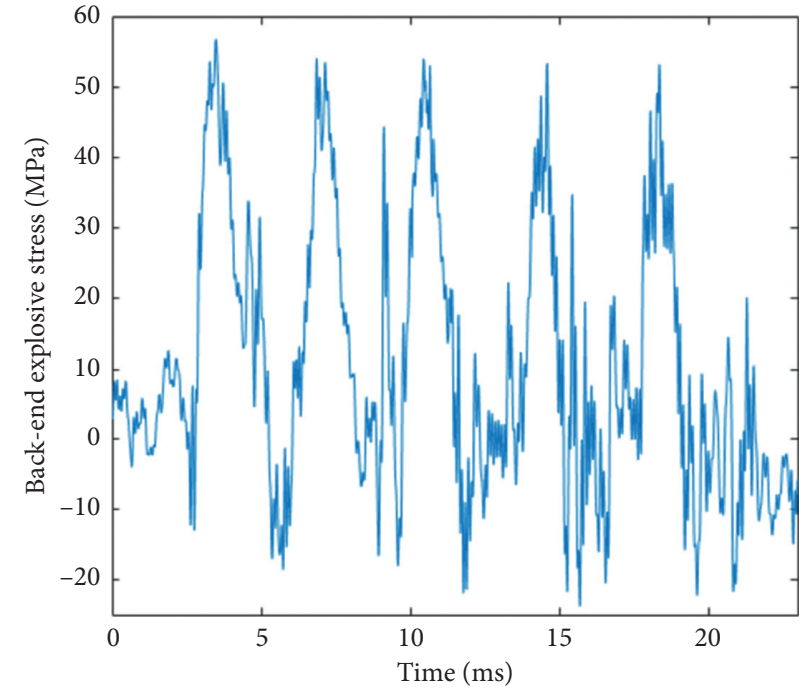

(b)

FIGURE 13: Stress curves in front end and back end of the explosive. 
TABLE 4: Simulation results, experiment results, and relative errors.

\begin{tabular}{lcccccc}
\hline & \multicolumn{2}{c}{$\begin{array}{c}\text { Front-end explosive stress } \\
(\mathrm{MPa})\end{array}$} & \multicolumn{2}{c}{$\begin{array}{c}\text { Back-end explosive stress } \\
(\mathrm{MPa})\end{array}$} & \multicolumn{2}{c}{ Relative error } \\
& Simulation & Experiment & Simulation & Experiment & Front end (\%) & Back end (\%) \\
\hline 1st target & 98.2 & 101.6 & 56.2 & 56.9 & 3.46 & 1.25 \\
2nd target & 91.5 & 94.7 & 56.3 & 54.2 & 3.49 & 3.73 \\
3rd target & 92.3 & 91.8 & 52.1 & 54.3 & 5.54 & 1.85 \\
4th target & 92.1 & 90.4 & 51.9 & 53.5 & 5.02 & 3.08 \\
5th target & 91.7 & 87.1 & 50.9 & 53.3 & & 5.72 \\
\hline
\end{tabular}

and the minimum error is $1.25 \%$. Figure 13 also illustrates additional stress pulses, which are caused by the propagation, reflection, and superimposition of the stress waves. These pulses exist between the adjacent dominant stress pulses, which correspond with the simulation results. Considering the numerical error and the measurement error, the experimental results are in consistent with the simulation results.

\section{Conclusion}

This paper designed and fabricated a miniature SMS to measure the stress characteristics of the explosive confined in the penetrator during an extreme MTP process. In the SMS, the sensitive surface of the chosen piezoelectric pressure sensor is coplanar with the explosive surface to record the impact stress on the contact area between the explosive and the casing. Realized by the low-power-operation mechanism, the system has a low operating power of $0.7 \mathrm{~mW}$ during the standby period which lasts for 15 days.

The signal acquisition experiment demonstrates that the SMS has an excellent performance on data acquisition compared with the oscilloscope. The MTP numerical simulation reveals that a new impact stress pulse is generated on the front of the explosive after a single-layer penetration and it will propagate through the explosive. The maximum impact stress on the front end of the explosive is $98.2 \mathrm{MPa}$. The explosive also impacts the rear of the casing under the action of a tensile wave, which is generated as a result of a compression pulse reflected from the free explosive surface. The maximum impact stress on the back end of the explosive is $50.9 \mathrm{MPa}$. The front end of the explosive withstands higher compression stresses than other parts, and the particles inside the explosive also withstand tensile stresses with a maximum amplitude of $31.9 \mathrm{MPa}$. The adjoining explosive element and casing element have similar axial impact stresses, which verifies that the installation method of the pressure sensor is reasonable. The MTP experiment is carried out. The relative stress errors between the measurement results and the simulation results are lower than $5.02 \%$, showing that the SMS proposed in this paper is adequate for explosive stress measurement. This development method also shows its potential for dynamic physical parameter measurement in other harsh scenarios [31].

\section{Data Availability}

The data used to support the findings of this study are available from the corresponding author upon request.

\section{Conflicts of Interest}

The authors declare that there are no conflicts of interest regarding the publication of this paper.

\section{Acknowledgments}

This work was supported in part by the Nanjing University of Science and Technology under Research Start-Up Funds under Grant AE89991/032, the Fundamental Research Funds for the Central Universities under Grant 309181A8804, Natural Science Foundation of Jiangsu Province, China, under Grant BK20190464, and the ShortTerm Visiting Exchange Funds in the Nanjing University of Science and Technology.

\section{References}

[1] Y. D. Zhang, Z. C. Lu, and H. M. Wen, "On the penetration of semi-infinite concrete targets by ogival-nosed projectiles at different velocities," International Journal of Impact Engineering, vol. 129, no. 7, pp. 128-140, 2019.

[2] J. G. Shin, K. Park, and G. I. Kim, "Estimation of exit angle for oblique penetration using numerical analysis," Journal of Mechanical Science and Technology, vol. 32, no. 12, pp. 5767-5776, 2018.

[3] Y. Zhou, X. Liu, W. Jiang et al., "Theoretical insight into reaction mechanisms of 2, 4-dinitroanisole with hydroxyl radicals for advanced oxidation processes," Journal of Molecular Modeling, vol. 24, no. 2, 2018.

[4] G. Greneker and E. O. Rausch, "Wall characterization for through-the-wall radar applications," in Proceedings of the SPIE Defense and Security Symposium, Orlando, FL, USA, April 2008.

[5] T. L. Warren, M. J. Forrestal, and P. W. Randles, "Evaluation of large amplitude deceleration data from projectile penetration into concrete targets," Experimental Mechanics, vol. 54, no. 2, pp. 241-253, 2014.

[6] G. Hang, W. Yu, T. Wang et al., "Theoretical insights into the effects of molar ratios on stabilities, mechanical properties, and detonation performance of cl-20/hmx cocrystal explosives by molecular dynamics simulation," Journal of Molecular Modeling, vol. 23, no. 1, 2017.

[7] Z. Han, Z. Zhao, Z. Du, C. He, L. Zhao, and X. Cong, "Bis (1, 5-diamino-4-methyl-tetrazolium) hydrazinetetrazolate: synthesis, structure and energetic properties," RSC Advance, vol. 4, no. 64, pp. 33724-33729, 2014.

[8] H.-S. Kim and B.-S. Park, "Characteristics of the insensitive pressed plastic bonded explosive, dxd-59," Propellants, Explosives, Pyrotechnics, vol. 24, no. 4, pp. 217-220, 1999. 
[9] D. Ma, P. Chen, Q. Zhou et al., "Ignition criterion and safety prediction of explosives under low velocity impact," Journal of Applied Physics, vol. 114, no. 11, pp. 405-408, 2013.

[10] V. Y. Egorshev, V. P. Sinditskii, and S. P. Smirnov, "A comparative study on two explosive acetone peroxides," Thermochimica Acta, vol. 574, pp. 154-161, 2013.

[11] X. Dai, Q. Huang, F. Huang, M. Li, Y. Wen, and X. Liu, "The development of a confined impact test for evaluating the safety of polymer-bonded explosives during warhead penetration," Propellants, Explosives, Pyrotechnics, vol. 40, no. 5, pp. 665-673, 2015.

[12] S. Hanagud and X. Lu, "First principles - based equations of state for functionally graded materials," in Proceeding of the XXI International Congress of Theoretical and Applied Mechanics, Warsaw, Poland, August 2004.

[13] S. Lecume and P. Chabin, "Structural and chemical changes in pbx induced by rapid shear followed by compression," in Proceedings of the 12th International Detonation Symposium, San Diego, CA, USA, August 2002.

[14] K. S. Vandersall, C. M. Tarver, F. Garcia et al., "On the low pressure shock initiation of octahydro-1, 3, 5, 7-tetranitro-1, 3, 5, 7-tetrazocine based plastic bonded explosives," Journal of Applied Physics, vol. 107, no. 9, Article ID 094906, 2010.

[15] D. G. Tasker, "Novel circuits for energizing manganin stress gauges," in Proceedings of the 19th Biennial Conference of the APS Topical Group on Shock Compression of Condensed Matter, Tampa, FL, USA, June 2015.

[16] G. Zhang, Y. Zhao, Y. Zhao et al., "A manganin thin film ultrahigh pressure sensor for microscale detonation pressure measurement," Sensors, vol. 18, no. 3, p. 736, 2018.

[17] G. Li, D. Liu, and D. Schleh, "An innovative instrumented projectile for measuring impact-induced force history," $E x$ perimental Techniques, vol. 40, no. 4, pp. 1335-1339, 2016.

[18] P. C. Muller, E. F. Bukowski, G. L. Katulka, and P. Peregino, "Flight test and recovery of gun-launched instrumented projectiles using high-g onboard recording techniques," IEEE Transactions on Magnetics, vol. 43, no. 1, pp. 388-390, 2007.

[19] C. Glößner, S. Moser, R. Külls et al., "Instrumented projectile penetration testing of granular materials," Experimental Mechanics, vol. 57, no. 2, pp. 261-272, 2017.

[20] D. Carlucci and J. Vega, "Empirical relationship for muzzle exit pressure in a $155 \mathrm{~mm}$ gun tube," WIT Transactions on Modelling and Simulation, vol. 45, pp. 225-229, 2007.

[21] B. Galpin, V. Grolleau, S. Umiastowski, G. Rio, and L. Mahéo, "Design and application of an instrumented projectile for load measurements during impact," International Journal of Crashworthiness, vol. 13, no. 2, pp. 139-148, 2008.

[22] M. Malewski, D. M. J. Cowell, and S. Freear, "Review of battery powered embedded systems design for mission-critical low-power applications," International Journal of Electronics, vol. 105, no. 6, pp. 893-909, 2018.

[23] G. Stergiopoulos and D. Gritzalis, "Installing a base operating system," Hacking And Penetration Testing with Low Power Devices, pp. 27-54, Elsevier, Amsterdam, The Netherlands, 2015.

[24] W. Xu, J. Wang, J. Li, and H. Huang, "Theoretical analysis and simulation for penetration overload of a small size charge," Journal of Vibration and Shock, vol. 30, no. 7, pp. 96-100, 2011.

[25] S. K. Chidester, C. M. Tarver, A. H. Depiero et al., "Single and multiple impact ignition of new and aged high explosives in the Steven Impact Test," in Proceedings of the 11th AIP Topical Conference on Shock Compression, Snowbird, UT, USA, July 1999.
[26] https://intertechnology.com/Kistler/pdfs/Pressure_Model_ 217C_617C.pdf.

[27] S. Ge, W. Zhang, J. Sang, S. Yuan, G. V. Lo, and Y. Dou, "Mesoscale simulation to study constitutive properties of TATB/F2314 PBX," Materials, vol. 12, no. 22, p. 3767, 2019.

[28] W. Zhang, L. Chen, J. Xiong, and Y. Ma, "Ultra-high g deceleration-time measurement for the penetration into steel target," International Journal of Impact Engineering, vol. 34, no. 3, pp. 436-447, 2007.

[29] S. R. Beissel and G. R. Johnson, "An abrasion algorithm for projectile mass loss during penetration," International Journal of Impact Engineering, vol. 24, no. 2, pp. 103-116, 2000.

[30] T. J. Holmquist and G. R. Johnson, “A computational constitutive model for concrete subjected to large strains, high strain rates and high pressures," in Proceedings of the 14th International Symposium on Ballistics, Quebec, Canada, September 1993.

[31] E. R. Matheson, D. S. Drumheller, and M. R. Baer, "A coupled damage and reaction model for simulating energetic material response to impact hazards," in Proceedings of the AIP Conference Proceedings, Texel, The Netherlands, April 2000. 